\title{
ASSESSMENT OF LOW BONE MASS USING PERIPHERAL DUAL X-RAY ABSORPTIOMETRY (PDXA) IN DIFFERENT ETHNIC GROUPS
}

\author{
ASHOK KUMAR D*, MUHAMMED JAVAD M, SNEKHALATHA U
}

Department of Biomedical Engineering, SRM University, Kattankulathur, Tamil Nadu, India. Email: ashok.d@ktr.srmuniv.ac.in

Received: 04 May 2017, Revised and Accepted: 18 May 2017

ABSTRACT

Objectives: The main aim of this study was to assess the low bone mass in younger adults using peripheral dual X-ray absorptiometry (pDXA) and also to find the co-relational aspect of Indian, Nepal-Bhutan, and Afghanistan men.

Methods: In this study, 70 younger adults aged from 18 to 25 years were incorporated. In every adult, bone mineral density (BMD) of the left forearm (LF-BMD), right forearm (RF-BMD), left calcaneum (LC-BMD), and right calcaneum (RC-BMD) were measured by pDXA. The back-propagation neural network classifier is used in the classification of low bone mass and healthy controls, and the statistical tool was used to find the co-relational aspect of various BMD measurements.

Results: The LC-BMD positively correlated ( $\mathrm{p}<0.05$ ) with subject's body weight and body mass index (BMI) $\mathrm{r}=0.40$ in Indian men. The LC-BMD and RC-BMD were positively correlated ( $\mathrm{p}<0.05$ and $\mathrm{p}<0.01)$ with BMI ( $\mathrm{r}=0.549$ and $\mathrm{r}=0.63)$ in Nepal-Bhutan men. In Afghanistan men, LF-BMD and RF-BMD are positively correlated $(\mathrm{p}<0.05$ and $\mathrm{p}<0.01)$ with BMI $(\mathrm{r}=0.49$ and $\mathrm{r}=0.80)$. The accuracy of the classifier was found to be $94.3 \%$ and $97.1 \%$ with RF-BMD and RC-BMD in the total population.

Conclusion: The result suggested that the forearm and calcaneum BMD measured by pDXA shows statistically high significant correlation with BMI, which can be used for screening purpose, and also it will be helpful in the evaluation of low bone mass in the developing countries.

Keywords: Bone mineral density, Peripheral dual X-ray absorptiometry, Body mass index, Osteoporosis, Low bone mass, Forearm, Calcaneum.

(C) 2017 The Authors. Published by Innovare Academic Sciences Pvt Ltd. This is an open access article under the CC BY license (http://creativecommons. org/licenses/by/4. 0/) DOI: http://dx.doi.org/10.22159/ajpcr.2017.v10i9.19615

\section{INTRODUCTION}

Osteoporosis is a metabolic disorder which is due to low mineral content in the bone, and the risk of fracture is high, especially, in the post-menopausal women and older adults. The decreasing bone quality is common due to aging in all the population. The fractures in the area of the hip and vertebrae have a significant relationship with morbidity and also with mortality. In 2050, 50\% of the hip and vertebrae fractures will occur in the Asian countries. The factors considered for lowmineral content depend on aging, mineral content, Vitamin D, and different environmental conditions, and diet conditions are the major reason for the fractures [1].

In developing countries, the higher percentage of women (9-38\%) is affected than men (2-8\%) with this osteoporosis [2]. The gold standard method used to measure bone mineral density (BMD) for the diagnosis of osteoporosis is dual-energy X-ray absorptiometry (DXA) technique [3]. The major two techniques which involve in the assessment of peripheral sites are the quantitative ultrasound and peripheral DXA (pDXA). Out of these techniques, pDXA is preferable for screening purpose. The BMD measured in peripheral sites was forearm and calcaneus, as these two parts are the recommended site according to the World Health Organization, and the time consumption of the measurement is minimum when compared to the whole-body DXA.

Marwaha et al. [4] assessed the bone health with the use of pDXA in the total population of 1600 men and women above the age of 50 who are residing in Delhi. The peripheral measurement is alternative to DXA due to its portable size and the low cost. They identified that estimation of BMD using pDXA is enhanced when it combines with the clinical factors which are related to the fractures [5,6]. Alonge et al. [7] studied the prevalence of osteoporosis and factors associated with osteoporosis in 2401 older patients in Nigerian population using the pDXA machine.
The different aspects of peripheral densitometry have been reviewed by the International Society for Clinical Densitometry $[8,9]$ which includes the monitoring and diagnosis of forearm measurement using DXA [10].

To the best of our knowledge, there is a sparseness of data on osteoporosis in Nepal, Bhutan, and Afghanistan population using DXA measurement. Hence, it is very much needed to study the BMD of different ethnic groups to predict the future risk of osteoporotic fractures. The comparative study of BMD using DXA is required for different Asian population to predict the osteoporotic condition. The aim of the study was to assess the relationship between measured BMDs in different ethnic groups using pDXA.

\section{METHODS}

Subjects and study groups

A total of 70 males aged from 18 to 25 years of different ethnic groups have participated in the free screening camp for low bone mass assessment. The camp was conducted in the SRM hospital, kattankulathur, Tamil Nadu, India, during the month of February 2017. The health histories of the men were obtained using a simple questionnaire. The men with severe illness were excluded from the study. For all the men, body weight and height were measured, and body mass index $(\mathrm{BMI})\left(\mathrm{Kg} / \mathrm{m}^{2}\right)$ was calculated.

In this study, the following approach was used to divide the total population.

Approach: Based on gender, men with different ethnics were subdivided into three groups as:

- Group 1: Indian men

$(\mathrm{n}=33$, mean \pm standard deviation $(\mathrm{SD})$ age $=20.12 \pm 1.02$ years $)$

- Group 2: Nepal and Bhutan men 
$(\mathrm{n}=20$, mean \pm SD age $=21.25 \pm 2.52$ years $)$

- Group 3: Afghanistan men

$(n=17$, mean \pm SD age $=23.17 \pm 1.94$ years $)$.

\section{Measurements}

The BMD of forearm and calcaneus of each male was measured using standard peripheral bone densitometer (EXA 3000, Osteosys Corporation, Korea). The quality assurance test was done daily using a standard phantom provided by the manufacturer.

i. Forearm: Left forearm (LF-BMD) $\left(\mathrm{g} / \mathrm{cm}^{2}\right)$ and right forearm (RF-BMD) $\left(\mathrm{g} / \mathrm{cm}^{2}\right)$

ii. Calcaneus: Left calcaneum (LC-BMD) $\left(\mathrm{g} / \mathrm{cm}^{2}\right)$ and right calcaneum (RC-BMD) $\left(\mathrm{g} / \mathrm{cm}^{2}\right)$

\section{Back-propagation neural (BPN) classification}

The gradient BPN network was used for classification of men into the healthy and low bone mass group. This classifier was tested using the following four attributes: (i) Age (years), (ii) body height $(\mathrm{cm})$, (iii) body weight $(\mathrm{Kg})$, and (iv) $\mathrm{BMI}\left(\mathrm{Kg} / \mathrm{m}^{2}\right)$ given as the input features for the total studied population.

\section{Statistical analysis}

The data were performed with the SPSS version 17.0 (SPSS Inc., Chicago, USA). The association between demographic features of different ethnic groups was compared with the measured forearm and calcaneum BMD values using pDXA.

\section{RESULTS}

\section{Statistical correlation}

Table 1 shows the statistical correlation matrix between measured demographic features compared with BMD variables by pDXA in total study men $(n=33$, mean \pm SD age $=20.12 \pm 1.02$ years $)$. The LC-BMD positively correlated $(\mathrm{p}<0.05)$ with subject's body weight and BMI $(\mathrm{r}=0.40)$. Table 2 shows the statistical correlation matrix between measured demographic features compared with BMD variables by pDXA in Nepal and Bhutan men $(n=20$, mean \pm SD age $=21.25 \pm 2.52$ years $)$. The RC-BMD negatively correlated $(\mathrm{p}<0.05)$ with subject's age $(\mathrm{r}=0.48)$, and calcaneum BMD (LC-BMD and RC-BMD) is positively correlated $(\mathrm{p}<0.05$ and $\mathrm{p}<0.01)$ with BMI $(\mathrm{r}=0.549$ and $\mathrm{r}=0.63)$. Table 3 shows the statistical correlation matrix between measured demographic features compared with BMD variables by pDXA in Afghanistan men $(\mathrm{n}=17$, mean \pm SD age $=23.17 \pm 1.94$ years). The LC-BMD and RC-BMD negatively correlated $(\mathrm{p}<0.05$ and $\mathrm{p}<0.01)$ with subject's age $(\mathrm{r}=0.51$ and $r=0.74$ ), and forearm BMD (LF-BMD and RF-BMD) is positively correlated $(\mathrm{p}<0.05$ and $\mathrm{p}<0.01)$ with BMI $(\mathrm{r}=0.49$ and $\mathrm{r}=0.80)$.
Comparison of Indian Men and Nepal-Bhutan men

Table 4 depicts the statistical differences between Indian men $(n=33)$ and Nepal-Bhutan men $(n=20)$. The mean age of both men groups was $20.12 \pm 1.02$ and $21.05 \pm 2.26$ years, respectively. The body weight, height, and BMI were statistically significant at the level of $p<0.01$. The measured BMD by pDXA at the regions of interest of the forearm BMD was lesser in Indian men group compared to Nepal-Bhutan group, with a reduction rate of $4 \%$, whereas in calcaneum $\mathrm{BMD}$, a reduction rate of $9 \%$ and $6 \%$ for RC-BMD and LC-BMD, respectively.

\section{Comparison of Indian men and Afghanistan men}

Table 5 depicts the statistical differences between Indian men $(n=33)$ and Afghanistan men $(n=20)$. The mean age of both men groups was $20.12 \pm 1.02$ and $23.18 \pm 1.94$ years, respectively. The body weight was statistically significant at the level $(\mathrm{p}<0.05)$. The measured BMD by pDXA at the regions of interest of the both forearm BMDs was lesser in Indian men group compared to Afghanistan group, with a reduction of $15 \%$, and it is statistically significant at the level of $p<0.01$. In the calcaneum BMD, a reduction rate was $17 \%$ and $11 \%$ for RC-BMD and LC-BMD, respectively, but the RC-BMD was statistically significant at the level of $\mathrm{p}<0.01$.

\section{Performance of classification}

The execution of characterization was assessed utilizing a confusion matrix. From this matrix, an accuracy of the classifier was assessed. The forward back-propagation network (BPN) was implemented for diagnosing low bone mass in both Indian men and other ethnic group men using right forearm. The sensitivity, specificity, and accuracy of the classifier were obtained as $95.7 \%, 91.7 \%$, and $94.3 \%$, respectively, in the right forearm region. In the case of right calcaneum region, the sensitivity, specificity, and the accuracy were observed to be $100 \%, 96 \%$, and $97.1 \%$, respectively. Figs. 1 and 2 demonstrated the performance classification of BPN classifier in the assessment of low bone mass in the right forearm and right calcaneum in the aggregate contemplated population.

\section{DISCUSSION}

Osteoporosis is the disease related to low mineral content that has less awareness associated with the diagnosis of low BMD in the developing countries [11]. The prevalence of this disease is increased in the age above 50 , and it was found that the prevalence rate is $20.3 \%$ in India [12]. In younger adults, tobacco and smoking have the significant dose-response association with osteoporosis [13], but the relationship with alcohol and osteoporosis is not clear [14]. Several authors have conducted the study on assessment on osteoporosis and suggested

Table 1: Statistical correlation matrix between measured demographic features and pDXA in total studied Indian men population $(n=33)$

\begin{tabular}{|c|c|c|c|c|c|}
\hline Method & Variable & LF-BMD $\left(\mathrm{g} / \mathrm{cm}^{2}\right)$ & $\operatorname{RF}-B M D\left(\mathrm{~g} / \mathrm{cm}^{2}\right)$ & LC-BMD $\left(\mathrm{g} / \mathrm{cm}^{2}\right)$ & RC-BMD $\left(\mathrm{g} / \mathrm{cm}^{2}\right)$ \\
\hline \multirow[t]{4}{*}{ Demographic features } & Age (years) & 0.278 & 0.020 & -0.020 & 0.150 \\
\hline & Body height $(\mathrm{cm})$ & -0.030 & 0.198 & 0.035 & 0.195 \\
\hline & Body weight (Kg) & -0.008 & -0.158 & $0.402^{*}$ & 0.304 \\
\hline & $\mathrm{BMI}\left(\mathrm{Kg} / \mathrm{m}^{2}\right)$ & -0.001 & -0.265 & $0.397^{*}$ & 0.213 \\
\hline
\end{tabular}

Pearson correlation coefficient $(\mathrm{r}),{ }^{*} \mathrm{p}<0.05$, LF-BMD: Left forearm bone mineral density, RF-BMD: Right forearm bone mineral density, LC-BMD: Left calcaneum bone mineral density, RC-BMD: Right calcaneum bone mineral density, p-DXA: Peripheral dual X-ray absorptiometry, BMI: Body mass index

Table 2: Statistical correlation matrix between measured demographic features and pDXA in total studied Nepal and Bhutan men population $(n=20)$

\begin{tabular}{|c|c|c|c|c|c|}
\hline Method & Variable & LF-BMD $\left(\mathrm{g} / \mathrm{cm}^{2}\right)$ & RF-BMD $\left(\mathrm{g} / \mathrm{cm}^{2}\right)$ & LC-BMD $\left(\mathrm{g} / \mathrm{cm}^{2}\right)$ & $\mathrm{RC}-\mathrm{BMD}\left(\mathrm{g} / \mathrm{cm}^{2}\right)$ \\
\hline \multirow[t]{4}{*}{ Demographic features } & Age (years) & 0.302 & 0.338 & -0.353 & $-0.483^{*}$ \\
\hline & Body height $(\mathrm{cm})$ & 0.179 & 0.324 & -0.041 & -0.056 \\
\hline & Body weight (Kg) & 0.011 & 0.035 & 0.334 & 0.414 \\
\hline & $\mathrm{BMI}\left(\mathrm{Kg} / \mathrm{m}^{2}\right)$ & -0.146 & -0.218 & $0.490 *$ & $0.629^{* *}$ \\
\hline
\end{tabular}

Pearson correlation coefficient ( $\mathrm{r}),{ }^{* *} \mathrm{p}<0.01,{ }^{*} \mathrm{p}<0.05$, LF-BMD: Left forearm bone mineral density, RF-BMD: Right forearm bone mineral density, LC-BMD: Left calcaneum bone mineral density, RC-BMD: Right calcaneum bone mineral density, p-DXA: Peripheral dual X-ray absorptiometry, BMI: Body mass index 
Table 3: Statistical correlation matrix between measured demographic features and pDXA in Afghanistan men population (n=17)

\begin{tabular}{|c|c|c|c|c|c|}
\hline Method & Variable & LF-BMD $\left(\mathrm{g} / \mathrm{cm}^{2}\right)$ & RF-BMD $\left(\mathrm{g} / \mathrm{cm}^{2}\right)$ & LC-BMD $\left(\mathrm{g} / \mathrm{cm}^{2}\right)$ & RC-BMD $\left(\mathrm{g} / \mathrm{cm}^{2}\right)$ \\
\hline \multirow[t]{4}{*}{ Demographic features } & Age (years) & 0.365 & 0.165 & $-0.514^{*}$ & $-0.748^{* *}$ \\
\hline & Body height $(\mathrm{cm})$ & -0.344 & -0.335 & $-0.520^{*}$ & $-0.526^{*}$ \\
\hline & Body weight (Kg) & 0.236 & $0.553^{*}$ & 0.066 & -0.200 \\
\hline & $\operatorname{BMI}\left(\mathrm{Kg} / \mathrm{m}^{2}\right)$ & $0.492^{*}$ & $0.802 * *$ & $0.494^{*}$ & 0.250 \\
\hline
\end{tabular}

Pearson correlation coefficient ( $\mathrm{r}),{ }^{* *} \mathrm{p}<0.01,{ }^{*} \mathrm{p}<0.05$, LF-BMD: Left forearm bone mineral density, RF-BMD: Right forearm bone mineral density, LC-BMD: Left calcaneum bone mineral density, RC-BMD: Right calcaneum bone mineral density, SD: Standard deviation, p-DXA: Peripheral dual X-ray absorptiometry, BMI: Body mass index

Table 4: Statistical differences in demographic features and pDXA measurements with Indian men and Nepal-Bhutan men population

\begin{tabular}{llll}
\hline Methods & Variable & Mean \pm SD & \\
\cline { 2 - 4 } & & Indian men (n=33) & Nepal and Bhutan men (n=20) \\
\hline significance (p value) & $20.12 \pm 1.02$ & $21.05 \pm 2.26$ \\
\hline Demographic features & Age (years) & $173.70 \pm 6.41$ & $168.90 \pm 6.40$ \\
& Body height $(\mathrm{cm})$ & $69.73 \pm 10.80$ & $61.77 \pm 7.37$ \\
p-DXA & Body weight $(\mathrm{Kg})$ & $23.15 \pm 3.39$ & $0.01^{* *}$ \\
& BMI $\left(\mathrm{Kg} / \mathrm{m}^{2}\right)$ & $0.48 \pm 0.10$ & $0.50 \pm 0.07$ \\
& RF-BMD $\left(\mathrm{g} / \mathrm{cm}^{2}\right)$ & $0.49 \pm 0.05$ & $0.01^{* *}$ \\
& LF-BMD $\left(\mathrm{g} / \mathrm{cm}^{2}\right)$ & $0.47 \pm 0.06$ & $0.65 \pm 0.12$ \\
$\mathrm{NC}-\mathrm{BMD}\left(\mathrm{g} / \mathrm{cm}^{2}\right)$ & $0.59 \pm 0.13$ & $0.63 \pm 0.12$ \\
\hline
\end{tabular}

${ }^{*}$ Correlation is significant at the 0.05 level (two-tailed), ${ }^{* *}$ correlation is significant at the 0.01 level (two-tailed), SD: Standard deviation, p-DXA: Peripheral dual X-ray absorptiometry, LF-BMD: Left forearm bone mineral density, RF-BMD: Right forearm bone mineral density, LC-BMD: Left calcaneum bone mineral density, RC-BMD: Right calcaneum bone mineral density, BMI: Body mass index

Table 5: Statistical differences in demographic features and pDXA measurements with Indian men and Afghanistan men population

\begin{tabular}{|c|c|c|c|c|}
\hline \multirow[t]{2}{*}{ Methods } & \multirow[t]{2}{*}{ Variable } & \multicolumn{2}{|l|}{ Mean \pm SD } & \multirow[t]{2}{*}{ Statistical significance ( $p$ value) } \\
\hline & & Indian men $(n=33)$ & Afghanistan men $(n=17)$ & \\
\hline \multirow[t]{3}{*}{ Demographic features } & Age (years) & $20.12 \pm 1.02$ & $23.18 \pm 1.94$ & $0.00^{* *}$ \\
\hline & Body weight (Kg) & $69.73 \pm 10.80$ & $76.68 \pm 5.51$ & $0.02^{*}$ \\
\hline & $\mathrm{BMI}(\mathrm{Kg} / \mathrm{m} 2)$ & $23.15 \pm 3.39$ & $24.83 \pm 1.77$ & NS \\
\hline \multirow[t]{4}{*}{ p-DXA } & RF-BMD $\left(\mathrm{g} / \mathrm{cm}^{2}\right)$ & $0.48 \pm 0.10$ & $0.57 \pm 0.07$ & $0.00^{* *}$ \\
\hline & LF-BMD $\left(\mathrm{g} / \mathrm{cm}^{2}\right)$ & $0.47 \pm 0.06$ & $0.55 \pm 0.07$ & $0.00^{* *}$ \\
\hline & $\mathrm{RC}-\mathrm{BMD}\left(\mathrm{g} / \mathrm{cm}^{2}\right)$ & $0.59 \pm 0.13$ & $0.71 \pm 0.11$ & $0.00^{* *}$ \\
\hline & LC-BMD $\left(\mathrm{g} / \mathrm{cm}^{2}\right)$ & $0.59 \pm 0.14$ & $0.66 \pm 0.11$ & NS \\
\hline
\end{tabular}

${ }^{*}$ Correlation is significant at the 0.05 level (two-tailed), ${ }^{* *}$ correlation is significant at the 0.01 level (two-tailed), SD: Standard deviation, p-DXA: Peripheral dual X-ray absorptiometry, LF-BMD: Left forearm bone mineral density, RF-BMD: Right forearm bone mineral density, LC-BMD: Left calcaneum bone mineral density, RC-BMD: Right calcaneum bone mineral density, BMI: Body mass index

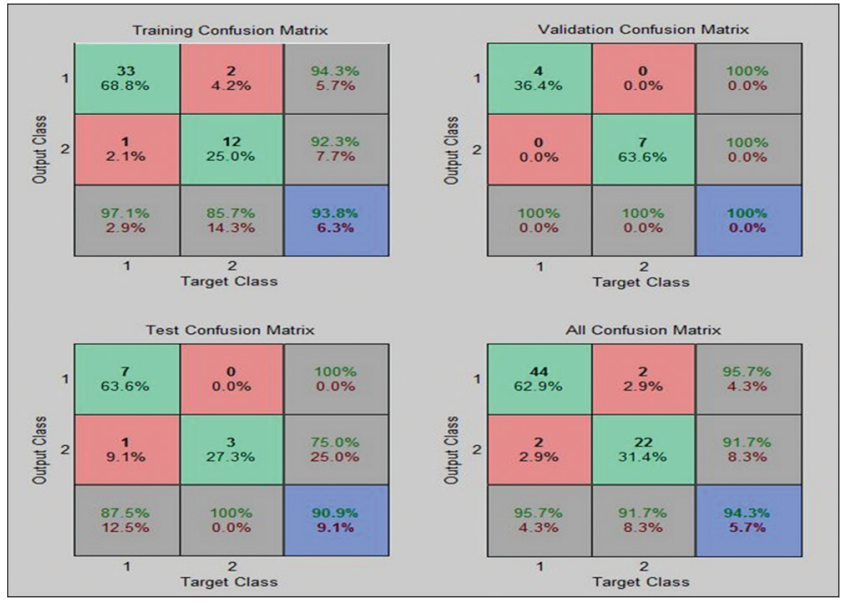

Fig. 1: Performance analysis of classifier in the evaluation of low bone mass in right forearm in the studied population

suitable therapy and food supplements to improve the quality of life [15-18]. The connection between body height and bone geometry

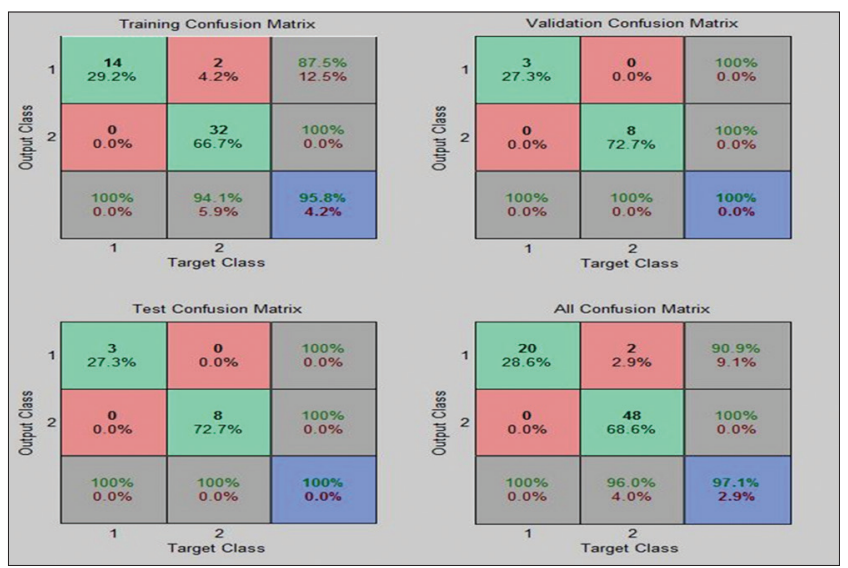

Fig. 2: Performance analysis of classifier in the evaluation of low bone mass in right calcaneum in the studied population

exists because the biomechanical strength applied to the skeleton [19]. The relationship between BMI, weight, height, and BMD was accounted for some populations [20-22]. 
Sapthagirivasan et al. showed that the bone mass reached its peak value in young Indian men whose age ranges from 26 to 30 years. They also compared the heel BMD with BMI and weight which shows the statistically significant value $(\mathrm{p}<0.01)$ [23]. In this study, the body weight and BMI showed a significant difference $(\mathrm{p}<0.05)$ with LC-BMD in Indian men, whereas in Nepal-Bhutan population, it showed a significant difference with LC-BMD ( $p<0.05)$ and with RC-BMD $(p<0.01)$. Bansal and Bansal [24] showed a similar kind of positive relationship with BMI and BMD in Men. Misao et al. [25] studied the population of 199 men and were found that LF-BMD showed a significance of $\mathrm{p}<0.01$ with BMI. In this study, the Afghanistan men showed a significance of $\mathrm{p}<0.05$ in LF-BMD and RF-BMD $(\mathrm{p}<0.01)$ with BMI

Cui et al. reported in their study that the participants with a BMI of $<18.5$ had a higher incidence of osteoporosis than BMI $\geq 18.5$ in both males and females. They confirmed that the factors such as age, sex, weight, BMI, high-density lipoprotein cholesterol, and diabetes are significant predictors of osteoporosis in the Chinese people [26].

This study showed that Indian men have low BMD compared to NepalBhutan men, which showed a reduction of $4 \%$ in both LF-BMD and RF-BMD, whereas $9 \%$ and $6 \%$ reduction was found in RC-BMD and LC-BMD. In comparison with Afghanistan men, a reduction rate of $15 \%$ was identified in LF-BMD and RF-BMD, whereas in RC-BMD and LC-BMD, the reduction rate was $17 \%$ and $11 \%$.

The classifier was tested with RF-BMD and RC-BMD, where these two had a higher reduction of BMD in Indian men compared to other ethnic groups. The accuracy of the classifier was found to be $94.3 \%$ in RF-BMD and $97.1 \%$ in RC-BMD.

\section{CONCLUSION}

It was found that Indian men have low BMD compared to other ethnic groups. The results suggested that both forearm and calcaneum BMD will be useful in the diagnosis of low bone mass. The classifier showed a good accuracy between both normal and low bone mass, and it could be tested for the large group of data. The main limitations of this study are a limited number of men included in all ethnic groups. The measurement of BMD using pDXA can be used as a screening tool for the rural people, especially in the developing countries.

\section{ACKNOWLEDGMENT}

The authors would like to express their gratitude to the health care authorities of SRM Hospital and Research Centre and Faculty of Engineering and Technology, SRM University, for providing the required facilitative infrastructure.

\section{REFERENCES}

1. Dhanwal DK, Cooper C, Dennison EM. Geographic variation in osteoporotic hip fracture incidence: The growing importance of asian influences in coming decades. J Osteoporos 2010;2010:757102.

2. Wade SW, Strader C, Fitzpatrick LA, Anthony MS, O’Malley CD. Estimating prevalence of osteoporosis: Examples from industrialized countries. Arch Osteoporos 2014:9:182.

3. Available from: http://www.apps.who.int/iris/bitstream/10665/42841/1/ WHO TRS 921.pdf. [Last accessed on 2017 Apr]

4. Marwaha RK, Tandon N, Garg MK, Kanwar R, Narang A, Sastry A, et al. Bone health in healthy Indian population aged 50 years and above. Osteoporos Int 2011;22(11):2829-36.

5. Cummings SR, Nevitt MC, Browner WS, Stone K, Fox KM, Ensrud KE, et al. Risk factors for hip fracture in white women. Study of osteoporotic fractures research group. N Engl J Med 1995;332(12):767-73.
6. Nevitt MC, Cummings SR, Stone KL, Palermo L, Black DM, Bauer DC, et al. Risk factors for a first-incident radiographic vertebral fracture in women $\geq 65$ years of age: The study of osteoporotic fractures. J Bone Miner Res 2005;20(1):131-40.

7. Alonge TO, Adebusoye LA, Ogunbode AM, Olowookere OO, Ladipo MM, Balogun WO, et al. Factors associated with osteoporosis among older patients at the geriatric centre in Nigeria: A cross-sectional study. S Afr Fam Pract 2017;1(1):1-7.

8. Hamdy RC, Petak SM, Lenchik L; International Society for Clinical Densitometry Position Development Panel and Scientific Advisory Committee. Which central dual X-ray absorptiometry skeletal sites and regions of interest should be used to determine the diagnosis of osteoporosis? J Clin Densitom 2002;5 Suppl: S11-8.

9. Miller PD, Njeh CF, Jankowski LG, Lenchik L; International Society for Clinical Densitometry Position Development Panel and Scientific Advisory Committee. What are the standards by which bone mass measurement at peripheral skeletal sites should be used in the diagnosis of osteoporosis? J Clin Densitom 2002;5 Suppl: S39-45.

10. Binkley N, Bilezikian JP, Kendler DL, Hans DB, Lewiecki EM, Silverman $\mathrm{S}$, et al. Official positions of the international society for clinical densitometry and executive summary of the 2005 position development conference. J Clin Densitom 2006;9(1):4-14.

11. Handa R, Kalla AA, Mahlouf G. Osteoporosis in developing countries. Best Pract Res Clin Rheumatol 2008;22(14):693-708.

12. Sharma S, Tandon VR, Mahajan A. Preliminary screening of osteoporosis and osteopenia in urban women from Jammu using calcaneal QUS. Indian J Med Sci 2006;60:183-9.

13. Ayo-Yusuf OA, Olutola BG. Epidemiological association between osteoporosis and combined smoking and use of snuff among South African women. Niger J Clin Pract 2014;17(2):174-7.

14. Maghraoui A, Ghazi M, Gassim S, Mounach A, Ghozlani I, Nouijai A, et al. Risk factors of osteoporosis in healthy Moroccan men. BMC Musculoskelet Disord 2010;11:148-53.

15. Varghese AP, Philip B, Kumar MK, Kuriakose F, Rodrigues PA. Assessment of osteoporosis and anemia risk in patients on anticonvulsant therapy. Int J Pharm Pharm Sci 2016;8:404-8.

16. Tripathy A, Adiga S, Shah HH, Shanbhag TV, Kumar DM. A retrospective study of clinical profile and drug prescribing pattern in osteoporosis in a Tertiary care hospital. Int $\mathrm{J}$ Pharm Pharm Sci 2015;7:390-3

17. Kale MA, Bindu SM, Khadkikar P. Role of antioxidants and nutrition in oxidative stress: A review. Int J Appl Pharm 2015;7:1-4

18. Pankova S, Tsvetkova D. Role of phytoestrogens in prevention of osteoporosis. Int J Curr Pharm Res 2015;7:1-6.

19. Damilakis J, Vlasiadis K. Have panoramic indices the power to identify women with low BMD at the axial skeleton? Phys Med 2011;27(1):39-43.

20. Devlin H, Horner K. Mandibular radiomorphometric indices in the diagnosis of reduced skeletal bone mineral density. Osteoporos Int 2002;13:373-8.

21. Mohan KB, Sapthagirivasan V, Anburajan M. Community-specific BMI cutoff points for South Indian females. J Obes 2011;1(1):1-8.

22. Estera MA, Vidmantas A, Vytaute P, Marija T, Rasmute M. Relationship between mandibular cortical bone height and bone mineral density of lumbar spine. Stomatol Balt Dent Maxillofac J 2008;10:72-5.

23. Sapthagirivasan V, Anburajan M. Heel bone mass of a young South Indian population with a Nigerian population residing in a South Indian suburban neighborhood: A comparative study. Osteoporos Int J 2012;23:2661-9.

24. Bansal A, Bansal S. Relationship of body mass index and bone mineral density in adult men. Int J Med Dent Sci 2016;5:1033-7.

25. Arimatsu M, Kitano T, Kitano N, Futatsuka M. Correlation between bone mineral density and body composition in Japanese females aged 18-40 years with low forearm bone mineral density. Environ Health Prev Med 2009;14(1):46-51.

26. Cui R, Zhou L, Li Z, Li Q, Qi Z, Zhang J. Assessment risk of osteoporosis in Chinese people: Relationship among body mass index, serum lipid profiles, blood glucose, and bone mineral density. Clin Interv Aging 2016;11:887-95. 